\title{
A STUDY OF UNMANNED GLIDER DESIGN, SIMULATION, AND MANUFACTURING
}

\author{
Anil Demircali, ${ }^{1}$ Huseyin Uvet $^{2}$
}

\begin{abstract}
This paper describes a mini unmanned glider's design, simulation, and manufacturing with a wing-folding mechanism. The mini-glider is designed for the CANSAT 2016 competition, which has the theme of a Mars glider concept with atmosphere data acquisition. The aim is to facilitate transportation and to land it to the destination point. Having a light and compact design is important since it is a glider without an engine and it uses power only for the transmission of sensory data. The glider is produced with a wingspan which is $440 \mathrm{~mm}$, and its longitudinal distance is $304 \mathrm{~mm}$. The wings can be packaged in a fixed size container whose dimensions are $125 \mathrm{~mm}$ in diameter and $310 \mathrm{~mm}$ in height. The glider's weight is only $144 \mathrm{gr}$, and it can increase up to $500 \mathrm{gr}$ with maximum with payload. The mechanism, which includes springs and neodymium magnets for wing-folding, is capable of being ready in $98 \mathrm{~ms}$ for gliding after separation from its container. The mini-glider is capable of telemetry, communications, and other sensory operations autonomously during flight.
\end{abstract}

UDC Classification: 621.7; DOI: http://dx.doi.org/10.12955/cbup.v5.1072

Keywords: MAV, Autonomous System, Wing-Folding, Reconnaissance

\section{Introduction}

The international CANSAT competition concept is somehow identical to typical gun-launched airvehicle systems (Lozano et al., 2013). The wing-folding structure allows it to be covered with a small volume and thus to be placed in a protective container (Steven, 2007). Recent research and industrial works related to gun-launched drones are principally focused on foldable fixed-wing configurations (Koehl, Arnaud, et al., 2012; Wood et al., 2014). Our goal in this work is to ensure that the wingfolding mechanism opens quickly and reliably immediately after separation from the rocket. It must fulfill its assigned tasks successfully in terms competition regulations (CanSat, 2016). In order to gather information about the atmosphere, there are fixed-wings and larger-sized heavier systems (U. S. Navy, 2004) or measurements with different approaches (Ru-Shan et al., 2015; Philipona et al., 2016) instead of foldable wing systems. As a matter of fact, in many control applications in order to find an optimal solution for a stable glider flight, PID, Adaptive and Neural network are widely used. However, in our scenario, a phugoid mode is necessary, thus our system is a glider and will not have any motors assembled. Meanwhile, we designed the glider systems' center of gravity and the inertia matrices, we conducted a production that would ensure that the system would fly in a phugoid mode. At this point, the system has already had mechanical control embedded (Smith, Andrew J., 2015).

Our aim is to combine all electronic equipment such as telemetry, communications, and sensory operations into a small PCB (Printed Circuit Board) card while maintaining a light and compact design. Our work is not just a mini-glider production for a competition, but it can also be used in areas with developments to be made in the future. Those areas are: transportation of medical and surgical supplies, search for chemical and radioactive areas, search and rescue operations, in communication systems, and agriculture. In our work, 6 degree of freedom movement systems were first created and simulations were done with the MATLAB/Simulink ${ }^{\circledR}$ program. The mechanical design and analysis of the planer were done in the 3D Solidworks ${ }^{\circledR}$ program, and the electronic card design is also made through the Proteus program. In the second part of the work, measurement models used with satellite kinematic and dynamic equations are presented. In the third part, the system and the simulated studies are analysed, and finally in the fourth part, the result section was discussed and evaluated.

\section{Mathematical Model}

In this section, the small wing-folding glider's dynamic properties are expressed as fundamental calculations. The wing design, dynamic model of the glider, and the aerodynamics calculations are given in detail. The basic principles of hovering flight can be demonstrated with a MATLAB ${ }^{\circledR}$ simulation after autonomous separation of the glider from the container (Cox et al., 2003; Bachuta, M. J., et al., 2012). The glider is designed in accordance with the rule stating: "the container shall fit in a cylindrical envelope". The operational scheme as shown in Figure 1 is in compliance with the

\footnotetext{
${ }^{1}$ Yildiz Technical University, Department of Mechatronics Engineering, Istanbul, Turkey, demircalianil@ gmail.com

${ }^{2}$ Yildiz Technical University, Department of Mechatronics Engineering, Istanbul, Turkey, huvet@ yildiz.edu.tr
} 
CANSAT 2016 competition rules (CanSat, 2016). Firstly, operational schematic should be known and should be expressed as in Figure 1. The glider is launched from point A and follows the trajectory B, it is separated from the capsule at point $\mathrm{C}$, which is 600 meters above ground level. The glider has to be separated autonomously at point $\mathrm{D}$ at the height of 400 meters and the collected data during the flight has to be observed by the ground station at point $\mathrm{F}$.

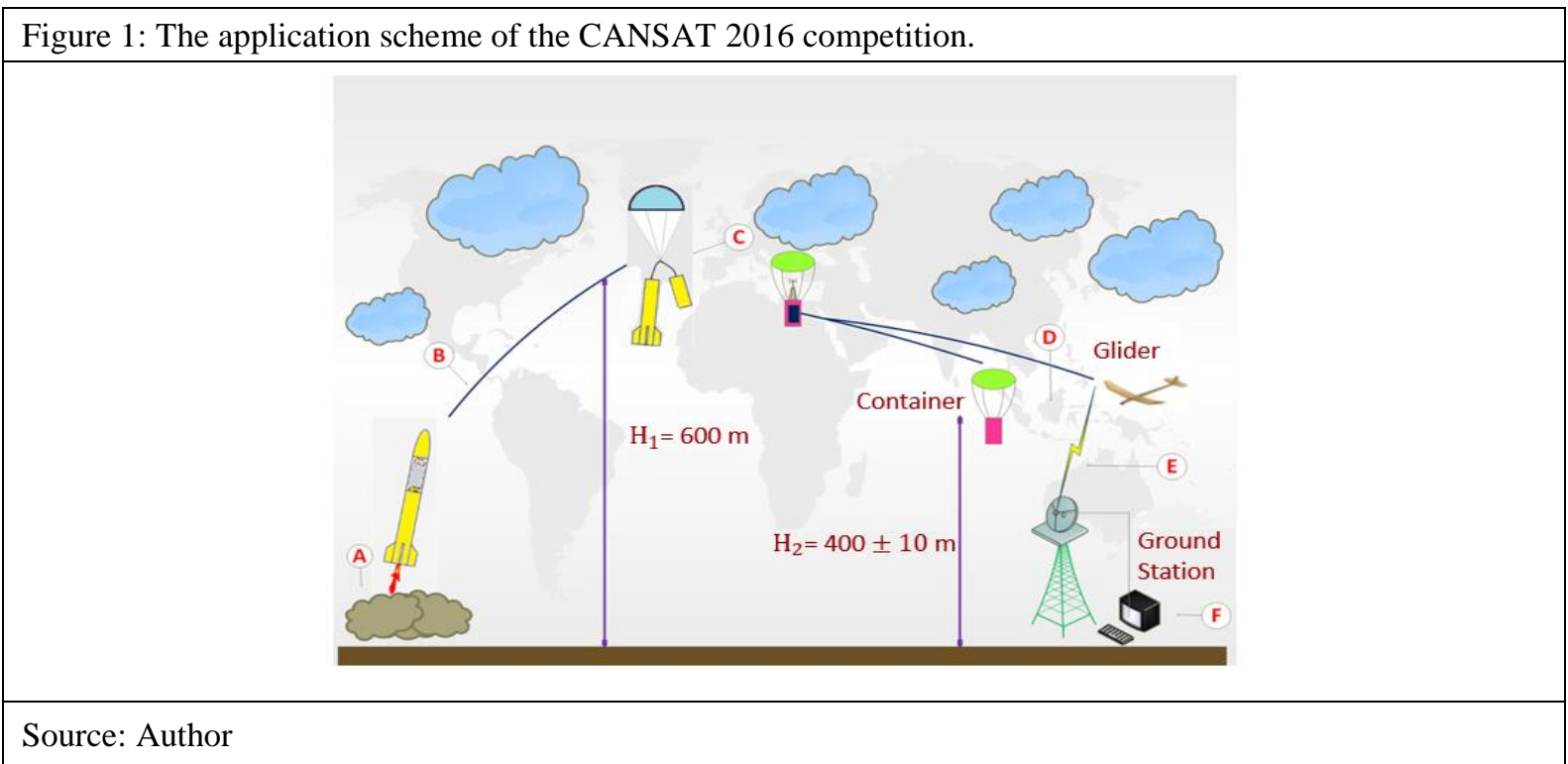

\section{Wing Design}

The glider's longitudinal length and wingspan of the folding position are imposed by the container size. The pre-designed model and container including the materials are shown in Figure 2. In order to determine the dynamic behavior of the glider, lift coefficient $C_{L, \text { required }}$ must be calculated according to the maximum pre-designed glider's established mass. Also, the thrust force of the glider should be observed under gliding condition together with the drag coefficient $C_{D}$ acting on it. The pre-designed container mass is calculated as 248 gr by using Kevlar. Then, it is important to determine $C_{L, \text { required }}$ with respect to the glider's maximum estimated mass $(252 \mathrm{gr})$. The maximum hovering speed $V_{\max }$ $(\mathrm{m} / \mathrm{s})$ can be calculated by determining the $C_{D, 0}$.

Figure 2: Container sizes are determined according to the standards of the competition. Eppler 793 Airfoil, $C_{L}$, $C_{M}, C_{D}, C_{L} / C_{D}$ graph results for $\alpha=-9.5^{\circ}$ to $9.5^{\circ}$ and Reynolds number, $\mathrm{Re}=5 \times 10^{4}$ with respect to estimated glide speed.
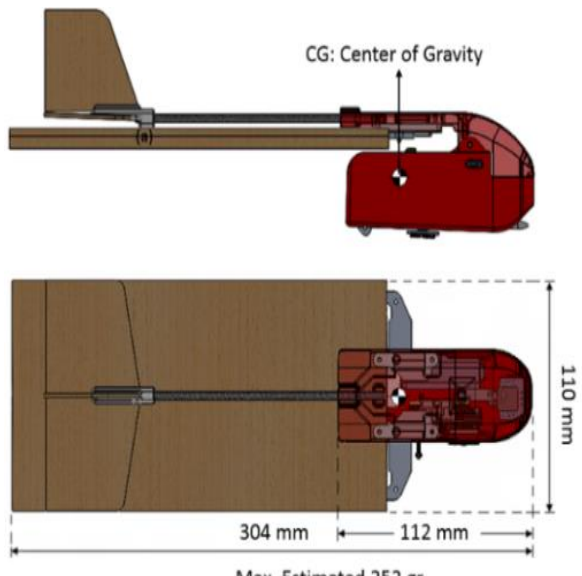

Max. Estimated $252 \mathrm{~g}$

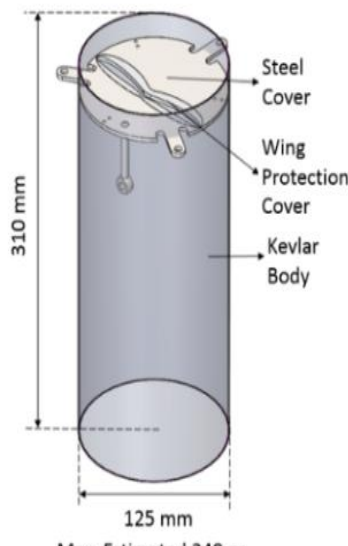

Max. Estimated 248
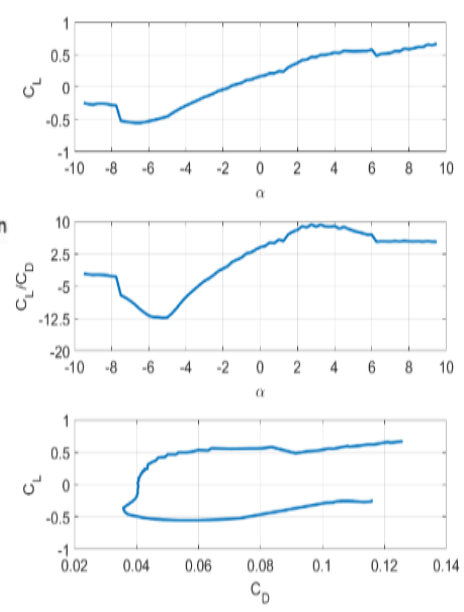

Source: Author

$C_{L} / C_{D}-\alpha$ graph allows the maximum lift coefficients $C_{L}$ to be described as a variable value of the AoA, which is selected $2^{\circ}-6^{\circ}$ to have maximum $C_{L}$. Also, similar stability effects are shown in $C_{M}-$ 
$\alpha$ for the same range of $\alpha$. By calculation of $\alpha=5.5^{\circ}$ from $C_{L}-\alpha$ graph showing stable and reliable flight can be observed. At the point of minimum drag $C_{D, 0}=0.07$ and (K:Aspect Ratio, $\mathrm{AR}$ ) $\mathrm{K}=9.466$ are determined for the determined AoA. Dynamic behaviour of the glider can be expressed,

$V=\sqrt{\frac{2 W}{\rho \pi C_{D} R^{2} \cos ^{2}\left(\frac{r \pi}{2 R}\right)}}$

$V_{\text {max }}=\sqrt{\frac{2 W}{\rho S} \sqrt{\frac{K}{C_{D, 0}}}}$

$C_{L}=\frac{2 L}{\rho S V^{2}}$

$K=\frac{1}{\pi A R e_{0}}$

$R e=\frac{\rho V \bar{c}}{\mu}$

where air density $\rho\left(\mathrm{kg} / \mathrm{m}^{3}\right.$, descending speed with container+payload $\mathrm{V}(\mathrm{m} / \mathrm{s})$, total wing area $\mathrm{S}=$ $0.0205\left(\mathrm{~m}^{2}\right)$, outer diameter of parachute $\mathrm{R}(\mathrm{m})$, inner diameter of parachute $\mathrm{r}(\mathrm{m})$, total mass $\mathrm{W}(\mathrm{N})$, drag force $\mathrm{D}(\mathrm{N})$ (Yechout, Thomas R., 2003). In that case, $C_{L}, V, V_{\max }, \alpha$ can be calculated and shown in Table 1.

\begin{tabular}{|l||c||c|}
\hline \multicolumn{2}{|l|}{ Table 1: Determination of the necessary parameters } \\
\hline \multicolumn{1}{|c|}{ Parameters } & Value & Unit \\
\hline $\boldsymbol{C}_{\boldsymbol{L}, \text { required }}$ & 0.4855 & - \\
\hline $\boldsymbol{V}_{(\text {total })}$ & 8.2 & $\mathrm{~m} / \mathrm{s}$ \\
\hline $\boldsymbol{V}_{(\text {container })}$ & 6.1 & $\mathrm{~m} / \mathrm{s}$ \\
\hline $\boldsymbol{V}_{\text {max }}$ & 12.5 & $\mathrm{~m} / \mathrm{s}$ \\
\hline $\boldsymbol{\alpha}$ & 5.5 & degree \\
\hline Source: Author & \\
\hline
\end{tabular}

The thrust force, which will determine enough lift to stable flight, can only be solved by introducing another equation or by determining of $C_{L, \text { required }}$. By using $V_{\text {total }}$ :(container+payload together) and $V_{\text {container }}$ :(container only) the descending speed and duration of the glide could be expressed. $V_{\max }$ represents the maximum lifting force of $\alpha$.

\section{The Dynamic Model of the Glider}

The primary goal of calculations is to determine the dynamic behavior of the glider. To obtain a simulation of the system, a mathematical model has to be derived by Newton motion laws with 6 degrees of freedom (DOF) (Garza, Frederico, Eugene A., 2003). Non-linear equations could be yielded,

$X-m g \sin (\theta)=m(\dot{U}+Q W-R V)$

$Y+m g \cos (\theta) \sin (\phi)=m(\dot{V}+R U-P W)$

$Z+m g \cos (\theta) \cos (\phi)=m(\dot{W}+P V-Q U)$

where glider mass $\mathrm{m}(\mathrm{kg})$, position $\mathrm{X}, \mathrm{Y}, \mathrm{Z}$, axial speeds $\mathrm{U}, \mathrm{V}, \mathrm{W}(\mathrm{m} / \mathrm{s})$, axial acceleration $\dot{U}, \dot{V}, \dot{W}$ $\left(\mathrm{m} / \mathrm{s}^{2}\right)$, and angular speeds $\mathrm{P}, \mathrm{Q}, \mathrm{R}(\mathrm{rad} / \mathrm{s})$. Axial acceleration can be expressed as (9-11) and angular speeds can be calculated as (12-14) where rolling moment $\mathrm{L}$, pitching moment $\mathrm{M}$, yawing moment $\mathrm{M}$. Axial acceleration and angular speeds are expressed,

$\dot{U}=R V-Q W-g \sin (\theta)+X / m$

$\dot{V}=P W-R U+g \cos (\theta) \sin (\phi)+Y / m$

$\dot{W}=Q U-P V+g \cos (\theta) \cos (\phi)+Z / m$

$\dot{P}=\left(c_{1} R+c_{2} P\right) Q+c_{3} L+c_{4} N$

$\dot{Q}=c_{5} P R-c_{6}\left(P^{2}-R^{2}\right)+c_{7} M$

$\dot{R}=\left(c_{8} P-c_{2} R\right) Q+c_{4} L+c_{9} N$ 
where $c_{1}=I_{x x}, c_{2}=-I_{x y}, c_{3}=-I_{x z}, c_{4}=-I_{y x}, c_{5}=I_{y y}, c_{6}=-I_{y z}, c_{7}=-I_{z x}, c_{8}=-I_{z y}, c_{9}=I_{z z}$ (Etkin, Bernard, Lloyd Duff Reid, 1996). By using (9-14) equations, and the glider stability analysis are done. Solving the equations of (9-14) yields Euler angle's derivatives in (15-17). The Euler angles could be expressed by,

$\dot{\phi}=P+\tan (\theta)(Q \sin (\phi)+R \cos (\phi))$

$\dot{\theta}=Q \cos (\phi)-R \sin (\phi)$

$\dot{\psi}=\frac{Q \sin (\phi)+R \cos (\phi)}{\cos (\theta)}$

By specifying the Euler angles, the resulting specific instant speed of the glider can be obtained which is defined on the body axis, then the equation (18-20) could be expressed including axial velocity,

$\dot{x}=U c(\theta) c(\phi)+V(s(\phi) s(\theta) c(\psi)-c(\phi) s(\psi))+W(c(\phi) s(\theta) c(\psi)+s(\phi) s(\psi))$

$\dot{y}=U c(\theta) s(\phi)+V(s(\phi) s(\theta) s(\psi)+c(\phi) c(\psi))+W(c(\phi) s(\theta) s(\psi)-s(\phi) c(\psi)$

$\dot{z}=-U s(\theta)+V(s(\phi) c(\psi))+W(c(\phi) c(\theta))$

where ( $\cos =\mathrm{c}, \sin =\mathrm{s})$. A method of evaluating the glider's positions on the airframe is to calculate the glide duration.

\section{Aerodynamics Calculation}

The goal of the XFLR5 ${ }^{\circledR}$ aerodynamic analysis is to determine the position of the glider on a X, Y, and $\mathrm{Z}$ axis after the instant speed of the glider is obtained in section $\mathrm{B}$. To determine the position of the glider, stability and control coefficients have to be calculated, which will be show in the (Figure 5). The results of the coefficients are shown in Table 2 where $\mathrm{X}$ direction $\mathrm{c}_{\mathrm{x}}, \mathrm{Y}$ direction $\mathrm{c}_{\mathrm{y}}, \mathrm{Z}$ direction $\mathrm{c}_{\mathrm{z}}$, rolling moment $\mathrm{c}_{1}$, pitching moment $\mathrm{c}_{\mathrm{n}}$, yawing moment $\mathrm{c}_{\mathrm{m}}$. The obtained coefficients are used to calculate X, Y, Z, L, M, N (Dilão, Rui, João Fonseca, 2013).

\begin{tabular}{|c|c|c|c|c|c|}
\hline \multicolumn{2}{|c|}{ Longitudinal } & \multicolumn{4}{|c|}{ Lateral } \\
\hline$c_{L, \alpha}$ & 4.8878 & $c_{y, \beta}$ & -0.36561 & $c_{l, r}$ & -0.22072 \\
\hline$c_{L, q}$ & 8.6232 & $c_{n, \beta}$ & 0.09735 & $c_{y, p}$ & -0.30632 \\
\hline$c_{m, \alpha}$ & -3.0688 & $c_{l, \beta}$ & -0.17966 & $c_{n, p}$ & -0.10115 \\
\hline$c_{m, q}$ & -20.781 & $c_{y, r}$ & 0.3857 & $c_{l, p}$ & -0.58491 \\
\hline & & $c_{n, r}$ & -0.12476 & & \\
\hline
\end{tabular}

The result of the designed model for the completed equipments are shown in Figure 3.

\begin{tabular}{l}
$\begin{array}{l}\text { Figure 3: The model is designed by 3D Solidworks } \\
\text { equipment. }\end{array}$ and shown as an isometric view including the \\
\hline Cource: Author \\
Communication \& GPS Unit
\end{tabular}


The communication \& GPS unit provide the glider's position, images are captured by camera during flight, when it is launched, the first separation inside of container, and after separation of container and glider happen. Moreover, the ground station should acquire flight information data during gliding which are provided by circuit board including variety of sensors such as a pitot tube, pressure, and altitude. A battery is used to provide the necessary energy. The equipment is modelled individually according to the weights on the sensitive scale; the center of gravity is placed of the wing's leading edge $(1 / 3)$ in the glider.

\section{Simulation and Analysis}

The designed model of the glider is given in Figure 3 of the mathematical model section. The analysis should be achieved with ready-made equipment in the design model to carried out further improvements easliy. Location of the center of gravity, estimation of the size of horizontal and vertical stabilizers and maximum lift were obtained in the previous section. The aim of the simulation is to compare parametric verification of the results with the calculations. Figure 3 in Aerodynamics Calculation section shows the completed design of the glider. To obtain the aerodynamic behaviour of the system, analysis is done by XFLR5 ${ }^{\circledR}$. The result is shown by using the Vortex lattice method, (VLM). It is applied for range of the $\alpha=-5^{\circ}$ to $15^{\circ}$ and $\mathrm{Re}=5 \times 10^{4}$ to $12.6 \times 10^{4}$ (Mueller, Thomas $\mathrm{J}$., 2001).

The most folding theories are concerning with either the speed of the stowed mechanism or its effect of the thrust force, but they neglect the strength of the wings and the folding mechanism. Deployment of the glider just needs a simple action from the user, since usage of basic components which are springs and magnets are shown in Figure 4.

Figure 4: Wings are deployed in $98 \mathrm{~ms}$. Left: Picture of instant position. Middle: The duration of deployment. Right: Picture of the completed deploy of the wings.

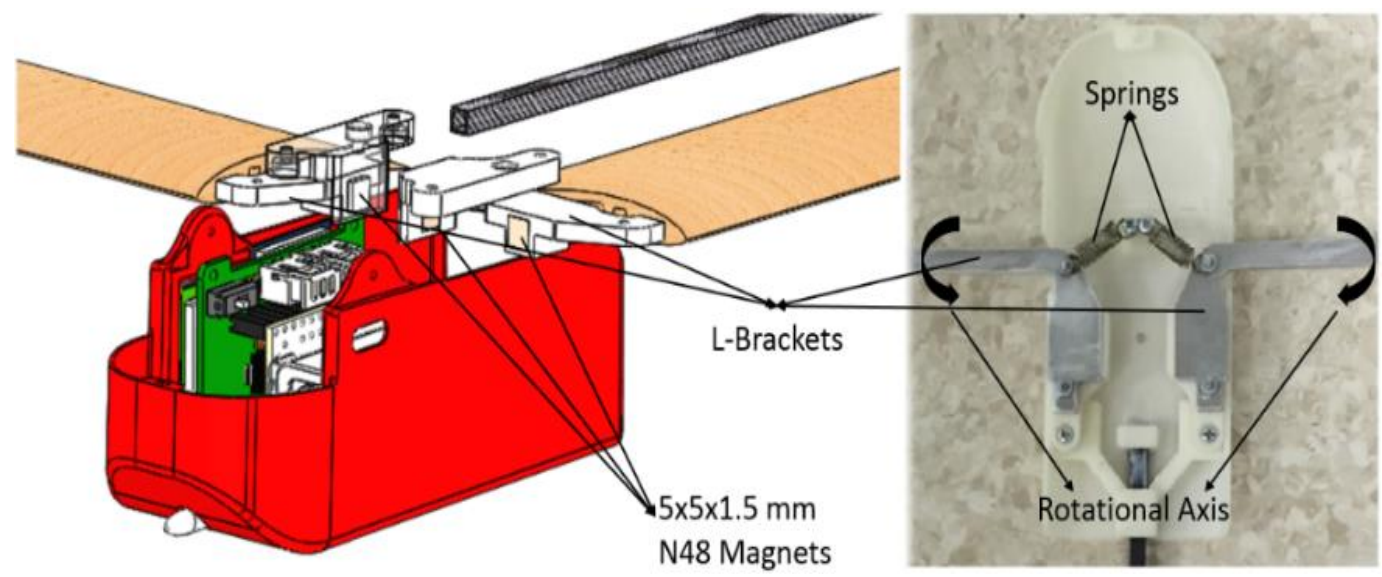

Source: Author

To verify the mathematical model of the system in SIMULINK ${ }^{\circledR}$, the weights of the equipment to be used must be taken into account. The hardware design of the glider is done in this way. For given simulation (figure 5), it is possible to observe the dynamic behavior of the glider. The Glider force and moment stability could be achieved during $13(\mathrm{~m} / \mathrm{s})$ flight speed and $\alpha=-3^{\circ}$. According to the obtained speed and $\alpha ; \mathrm{X}, \mathrm{Y}, \mathrm{Z}$ positions of glider and glide duration time could be calculated. Glide duration and helical path could be controlled by 2 different control input which are the elevator and the rudder. The helical path, whose diameter is a maximum $60 \mathrm{~m}$, could be followed when rudder $=1^{\circ}$ in 117.37.

During descent, at the first 1.5 cycle of descent path whose diameter has bigger helical cycles than remaining path, the glider does not reach limit speed which is required for stable state of phugoid motion. However, when the glider is about $310 \mathrm{~m}$ above ground level, equal helixes are seen since maximal speed is reached. Moreover, the glider is separated from the container with an initial speed of $0(\mathrm{~m} / \mathrm{s})$ so, the necessary time for landing must be calculated. It can also be noted that the helical path diameter from the longitudinal distance and lateral distance with respect to the time graphs show that 
stable flight takes 23.7 seconds to achieve. Also, linearity, which gives information about stable flight, could be seen from the height-time graph. As a result, the glider shall be stable around 310 meter above ground level and at 23.7 seconds after releasing. According to the analysis and the simulations, this section shows that the wing-folding structure is safe; the glider can fly and hover according to the operational rules.

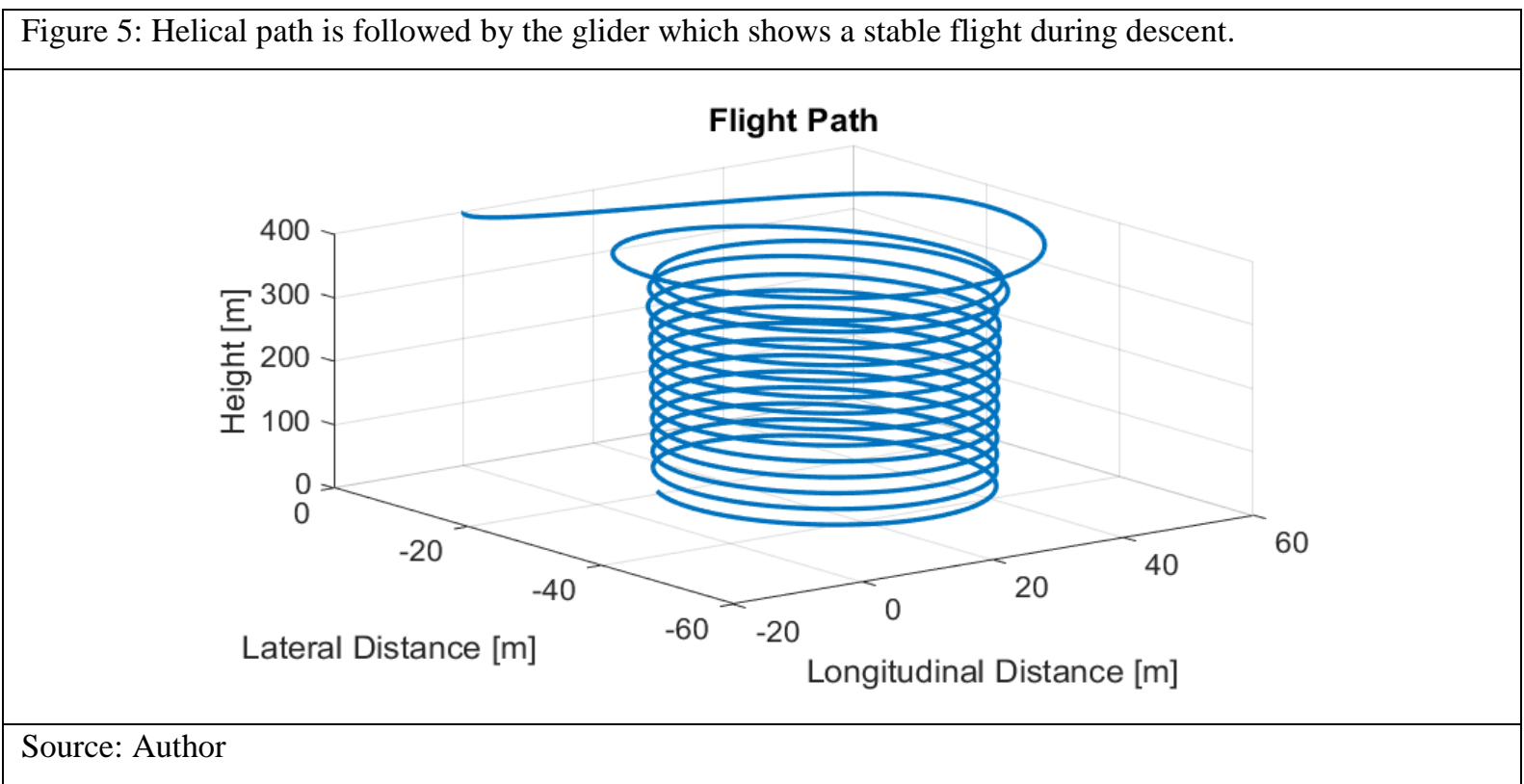

\section{Results}

Along with the direction of the iteration stages of the targeted criteria and the simulation, the wing design has been achieved successfully. The sizing studies have been optimized through the XFLR5® program. The wing angles, the position of the center of gravity and the static margin values were determined, depending on the polar plot of the selected wing profile and planer. The glider system, modeled in the Solidworks $3 \mathrm{D} \AA$ design program, has successfully opened its wings when it left the container, just as it did in the test result. The wing-folding mechanism works very well and fast as seen in Figure 6.

Figure 6: Wings are deployed in $98 \mathrm{~ms}$. Left: Picture of instant position. Middle: The duration of deploy. Right: Picture of the completed deployment of the wings.

\begin{tabular}{|lll}
\hline & \\
\hline &
\end{tabular}

The prototype was made using a 3D printer, successfully completing the competition goals.

\section{Acknowledgement}

This project with Project No: 113E584 is supported by The Scientific and Technological Research Council of Turkey (TUBITAK). 


\section{References}

Bachuta, M. J., et al. "UAV glider control system based on dynamic contraction method." Methods and Models in Automation and Robotics (MMAR), 2012 17th International Conference on. IEEE, 2012.

Beeler, Scott C., Daniel D. Moerder, and David E. Cox. "A flight dynamics model for a small glider in ambient winds." (2003).

Chauffaut, Corentin, Juan Escareno, and Rogelio Lozano. "The transition phase of a gun-launched micro air vehicle." Journal of Intelligent \& Robotic Systems70.1-4 (2013): 119-131.

Dilão, Rui, and João Fonseca. "Dynamic trajectory control of gliders." Advances in Aerospace Guidance, Navigation and Control. Springer Berlin Heidelberg, 2013. 373-386.

Etkin, Bernard, and Lloyd Duff Reid. "Dynamics of flight: stability and control.” Vol. 3. New York: Wiley, 1996.

Felton, S., Tolley, M., Demaine, E., Rus, D., I\& Wood, R. (2014). A method for building self-folding machines. Science, 345(6197), 644-646.

Gao, Ru-Shan, et al. "A Novel Approach to Atmospheric Measurements Using Gliding UASs." Dynamic Data-Driven Environmental Systems Science. Springer International Publishing, 2015. 10-15.

Garza, Frederico R., and Eugene A. Morelli. "A collection of nonlinear aircraft simulations in Matlab." (2003).

http://www.cansatcompetition.com

Koehl, Arnaud, et al. "Aerodynamic modelling and experimental identification of a coaxial-rotor UAV." Journal of Intelligent \& Robotic Systems 68.1 (2012): 53-68.

Kräuchi, Andreas, and Rolf Philipona. "Return glider radiosonde for in situ upper-air research measurements." Atmospheric Measurement Techniques 9.6 (2016): 2535-2544.

Landon, Steven D. "Development of deployable wings for small unmanned aerial vehicles using compliant mechanisms."

Mueller, Thomas J. "Fixed and flapping wing aerodynamics for micro air vehicle applications." Vol. 195. AIAA, 2001.

Smith, Andrew J. "Aerial Deployed Unfolding Autonomous Glider System." 53rd AIAA Aerospace Sciences Meeting. 2015.

U. S. Navy, "Sonobuoy Tube-launched UAV," STTR, Ed., 2004.

Yechout, Thomas R. Introduction to aircraft flight mechanics. Aiaa, 2003. 